\title{
A Universidade da Coruña: 25 anos de historia
}

\author{
The University of A Coruña: 25 Years of History
}

\author{
Narciso DE GABRIEL \\ Universidade da Coruña
}

\begin{abstract}
RESUMO: A Universidade da Coruña foi creada en 1989, aínda que a segregación dos centros e recursos que dependían da Universidade de Santiago non se produciu ata 1990. Despois de revisar os antecedentes desta institución, analizaremos a súa evolución institucional, profesorado, alumnado, persoal de administración e servizos, docencia e investigación. Este artigo é basicamente unha escolma da exposición titulada 25 anos de UDC. A Universidade na Coruña e Ferrol (A Coruña, Fundación Barrié, abril-setembro 2015).
\end{abstract}

PALABRAS CHAVE: Escolas profesionais, escolas técnicas, universidade, A Coruña, Ferrol

ABSTRACT: The University of A Coruña was created in 1989, although the centers and resources that were functioning under the University of Santiago did not become independent until 1990. After reviewing the recent history of this institution, this article goes on to analyze aspects such as its evolution as an institution, the faculty, the student body, administrative and services staff, teaching and research. This article is basically a selection from the exhibit entitled 25 years of the UDC: The University of A Coruña and Ferrol (A Coruña, Fundación Barrié, April-September 2015).

KEY WORDS: Professional schools, Technical schools, University, A Coruña, Ferrol

En 1989 aprobouse a Lei 11/1989 que daba orixe a dúas novas universidades en Galicia, a de Vigo, con campus en Ourense e Pontevedra, e a da Coruña, con campus en Ferrol, que se unían á de Santiago de Compostela, con campus en Lugo. Na súa exposición de motivos xustifícase a decisión de crear novas universidades atendendo á forte demanda de estudos universitarios en Galicia, que tiña daquela unha das "máis baixas taxas de escolarización universitaria de Europa", á saturación de determinados centros, á pretensión de ampliar o abano de titulacións e á necesidade de mellorar a calidade docente e investigadora, para o que resultaba imprescindible un incremento substancial do financiamento. ${ }^{1}$ Existían tamén outras razóns, ás que non se alude, como a dificultade de xestionar unha universidade, a de Compostela, con sete campus e un volume crecente de alumnado, persoal de administración e servizos e profesorado, ben como a presión exercida desde diversas instancias para crear novas universidades.

\footnotetext{
${ }^{1}$ Desenvolvemento do Sistema Universitario de Galicia (Santiago de Compostela: Xunta de Galicia, 1991): 245-246.
} 
No presente artigo, que no fundamental é unha escolma e resumo da parte textual da exposición titulada 25 anos de UDC. A Universidade na Coruña e Ferrol, da que fun comisario, examinaremos os antecedentes, algúns datos sobre a evolución institucional, os colectivos do profesorado, alumnado, o persoal de administración e servizos, a docencia e a investigación.

\section{Antecedentes}

A segregación dos centros dependentes da Universidade de Santiago de Compostela, e a súa simultánea integración na Universidade da Coruña (UDC), produciuse mediante o Decreto 3/1990, do 11 de xaneiro. ${ }^{2}$ En virtude deste decreto transferíanse os seguintes centros docentes propios á UDC: ${ }^{3}$

- Escola Universitaria de Formación do Profesorado de EXB

- Escola Universitaria de Empresariais

- Escola Universitaria Politécnica (Ferrol)

- Escola Universitaria de Arquitectura Técnica

- Escola Universitaria de Informática

- Escola Técnica Superior de Arquitectura

- Colexio Universitario

- Facultade de Dereito

Os dous primeiros centros tiñan unha longa historia, pois foran creados a mediados do século XIX, como tamén a Escola de Náutica, que se transferirá á UDC en 1990 (Decreto 8/1990, do 11 de xaneiro). ${ }^{4}$

A Escola Normal de Instrución Primaria, destinada á formación do maxisterio masculino, inaugurouse 02 de xullo de 1845 e estivo dirixida por Antonio María de la Iglesia. A súa duración foi curta, pois en 1849 o goberno reorganizou e reduciu o número de centros e adxudicou a Santiago de Compostela a Escola Normal Superior de Mestres, desatendendo as demandas que reclamaban a súa continuidade na cidade herculina.

Os estudos de Maxisterio retornaron á Coruña en 1865, agora con carácter feminino. Nace, así, a Escola Normal Superior de Mestras, que conservará este carácter ata a Segunda República, en que se aplicou por primeira vez a coeducación nos centros de formación do maxisterio. Durante o franquismo volverá practicarse a segregación por sexos. ${ }^{5}$

\footnotetext{
${ }^{2}$ Ibid., 257-264.

${ }^{3} \mathrm{~A}$ estes centros uníanse dous adscritos radicados na cidade da Coruña: a Escola de Enfermaría e o Instituto Nacional de Educación Física.

${ }^{4} \mathrm{~A}$ historia destas tres escolas profesionais aínda está por facer, polo que non podemos ofrecer unha síntese da súa evolución. Existen, no entanto, algunhas achegas das que nos facemos eco nas notas que seguen.

${ }^{5}$ José Luis Iglesias Salvado e María Dolores Cotelo Guerra, "Modelos de enseñanza y acreditación del magisterio femenino: La Escuela Normal Superior de Maestras de A Coruña (1880-1898)", en La acreditación de saberes y competencias. Perspectiva histórica (Oviedo: Universidad de Oviedo, 2001), 415-424.
} 
En 1850 creáronse as escolas oficias de Náutica e de Comercio, que inicialmente formaban un único centro docente, instalado no edificio do Real Consulado. O Consulado xa puxera en funcionamento este tipo de estudos, tan en harmonía co modo de ser da cidade, a finais do século XVIII, e a Xunta de Comercio encargouse de darlles continuidade no XIX. ${ }^{6}$

As clases de Náutica comezaron no curso 1851-1852, e un ano despois fixérono as de Comercio. Para aproveitar o reducido espazo existente, a primeira das titulacións tiña horario nocturno e a segunda diúrno.

Os estudos de Comercio incorporáronse ao instituto de ensino secundario, como "estudos de aplicación", no curso 1863-1864, e nel permaneceron durante 22 anos, que seguramente non foron os máis gloriosos da súa historia. En 1887 recuperaron a autonomía e desde esa data a 1908 a escola foi dirixida por Segundo Moreno Barcia, líder do republicanismo coruñés. Durante o seu mandato reivindicarase a transformación da escola nun centro de carácter superior, aspiración que se fará realidade en $1898{ }^{7}$

Náutica experimentou numerosos cambios na súa dilatada traxectoria. Unha vez separada de Comercio, funcionou como Escola Profesional de Náutica. O Estado deixou de financiala en 1869, e aínda que as xestións da deputación provincial conseguiron recuperar a actividade docente, o centro atravesou por fases críticas. En 1924 foi suprimido e non abrirá de novo as súas portas ata $1947 .^{8}$

Estes tres primeiros centros docentes tiveron que buscar acomodo, polo regular en condicións precarias, en diversos locais, pois careceron de edificios propios e específicos ata que se construíu a Cidade Escolar, cuxa historia se aborda neste mesmo número de Sarmiento. Os edificios de Comercio, Maxisterio e Náutica, construídos a partir dos anos corenta e deseñados polo arquitecto Antonio Tenreiro Rodríguez, configuran o primeiro campus da UDC, o campus de Riazor, no que actualmente só resta un centro docente, a Escola Técnica Superior de Náutica e Máquinas. $O$ antigo edificio de Comercio converteuse no Centro Universitario de Riazor, e no de Maxisterio está instalado o Espazo de Intervención Cultural Normal, así denominado atendendo ao seu uso orixinal.

A Escola de Enxeñaría Técnica Naval (inicialmente Peritos Navais e actualmente Escola Universitaria Politécnica) iniciou a súa traxectoria no curso académico 1966-1967 nas dependencias do Instituto Feminino de Ferrol. As clases deron comezo 03 de novembro, "unha data para a historia ferrolá", segundo titulaba La Voz de Galicia o día anterior. As obras do edificio que se construirá en Serantes iniciáronse en 1966 e a súa inauguración produciuse 06 de outubro de 1971. A prensa informaba de que o seu custo fora duns 66 millóns de pesetas, incluída a moblaxe e o material dos laboratorios e talleres. Nacía,

\footnotetext{
${ }^{6}$ Antonio Meijide Pardo, Origen y progresos de la Escuela de Náutica de La Coruña /1790-1825) (A Coruña: Real Academia Galega, 1963); Mª del Carmen Sánchez Rodríguez de Castro, El Real Consulado de La Coruña: impulsor de la llustración (1785-1833) (Sada: Ediciós do Castro, 1992).

${ }^{7}$ Enrique Fraga Rodríguez, Escuela de Comercio de La Coruña (A Coruña: Lit. e Imp. Roel, 1944); Antonio Meijide Pardo, Eusebio Da Guarda y el Instituto de 2ª Enseñanza de la Coruña (A Coruña: La Voz de Galicia, 1991).

${ }^{8}$ Francisco Blanco Filgueira, Escola Técnica Superior de Náutica e Máquinas (A Coruña: ETS de Náutica e Máquinas-UDC, 2007).
} 
daquela, o segundo dos campus da actual Universidade da Coruña e o primeiro da cidade de Ferrol.

Na década de 1970 créanse na Coruña a Escola de Arquitectura Técnica (Decreto 2501/1971) ${ }^{9}$ e a Escola Técnica Superior de Arquitectura (Decreto 2219/1973). Entre unha e outra data constituíuse o Colexio Universitario como centro adscrito á Universidade de Santiago; nel estaba previsto impartir os primeiros ciclos das facultades de Filosofía e Letras, Ciencias e Ciencias Económicas e Empresariais (especialidade de Empresariais; Decreto 2586/1972). Seis anos máis tarde acordouse a súa integración na Universidade de Santiago "como prolongación dos servizos" desta (Real decreto 3142/1978).

A Fundación Barrié financiou a construción na denominada Finca do Cura dos edificios destinados á Escola de Arquitectura Técnica e á Escola Técnica Superior de Arquitectura. Inicialmente pensábase nun proxecto arquitectónico unitario, formado por dous volumes rectangulares conectados, mais finalmente optouse por diferenciar e singularizar ambos os edificios. Primeiro construíuse o de Arquitectura Técnica, que comezou a funcionar en 1975, e logo o de Arquitectura Superior, inaugurado en 1980. Estes edificios, xunto co do Colexio Universitario, que comezou a ser utilizado en 1985, e o que actualmente acolle a Facultade de Filoloxía, conforman o campus da Zapateira. ${ }^{10}$

Polo demais, a partir de 1972, e ao abeiro do establecido na Lei xeral de educación (1970), as centenarias escolas de Comercio e Normal, e as máis recentes de Enxeñaría Técnica Naval e Arquitectura Técnica, pasaron a formar parte, como escolas universitarias, da Universidade de Compostela, ao igual que, xa desde os seus inicios, a Escola Técnica Superior de Arquitectura e as máis recentes Escola Universitaria de Informática (1986) e a Facultade de Dereito (1987). Desde 1978 tamén formaban parte da Universidade de Santiago, como centros adscritos, as escolas universitarias de Enfermaría da Coruña e Ferrol, e desde 1987 o Instituto Nacional de Educación Física, que dará lugar ao campus de Bastiagueiro. ${ }^{11}$

Así pois, cando en 1989 se decide crear a UDC, a cidade da Coruña xa dispuña dunha importante rede de centros de carácter universitario: cinco escolas universitarias, un colexio universitario -xermolo das actuais facultades de Ciencias, Filoloxía, Economía e Empresa e, parcialmente cando menos, Educación-, unha escola superior, unha escola técnica superior e unha facultade; e Ferrol, pola súa parte, contaba con dúas escolas universitarias. Esta situación, que se reproducía en termos similares nas outras cidades galegas, era o resultado dun dobre proceso: a transformación das antigas escolas profesionais e técnicas en escolas universitarias a raíz, como xa dixemos, da aprobación da Lei xeral de

\footnotetext{
${ }^{9}$ José M.- Yáñez Rodríguez e outros, Escuela Universitaria de Arquitectura Técnica "Pedro Barrié de la Maza". XXV aniversario (A Coruña: Fundación Pedro Barrié de la Maza, 1995).

${ }^{10}$ José Ramón Alonso Pereira e Antonio S. Río Vázquez, "Las Escuelas de Arquitectura de La Coruña. Una obra brutalista en el origen de un campus universitario", en Arquitetura moderna e internacional: conexões brutalistas, 1955-1975 (Curitiba: X Seminário DOCOMOMO, 2013).

${ }^{11}$ Alberto Areces Gayo, M. a José Mosquera González e Rafael Martín Acero, 25 anos da Facultade de Ciencias do Deporte e a Educación Física/INEF de Galicia (1986-2011) (A Coruña: INEF de Galicia-UDC, 2011).
} 
educación, e a descentralización da Universidade de Santiago de Compostela coincidindo cun período de forte expansión da demanda de estudos universitarios. ${ }^{12}$

\section{Algúns datos sobre a evolución institucional}

A UDC iniciou a súa andaina con José Antonio Portero Molina (Burgos, 1947), catedrático de Dereito Constitucional, como reitor comisario nomeado polo goberno da Xunta de Galicia presidido por Fernando González Laxe (DOG do 19 de setembro de 1989). 0 seu mandato foi breve, pois Manuel Fraga Iribarne, novo presidente da Xunta, cesouno o 31 de agosto de 1990, provocando unha importante polémica con notable repercusión nos medios de comunicación. Por estas datas a situación da UDC era aínda moi precaria, debido ás carencias de infraestruturas materiais e administrativas. De feito, a xestión aínda dependía en boa medida da universidade compostelá.

José Luís Meilán Gil (A Coruña, 1933), catedrático de Dereito Administrativo, foi designado reitor por Manuel Fraga Iribarne o mesmo día en que cesou o profesor Portero Molina. En 1991 converteuse no primeiro reitor elixido pola comunidade universitaria a través do seu claustro, cargo para o que será reelixido en 1993, 1996 e 2001. En conxunto, os seus mandatos abranguen algo máis da metade da historia da UDC, e ao longo deles sentáronse as bases desta institución. ${ }^{13} \mathrm{O}$ profesor Meilán cesou en setembro do 2003, unha vez cumprida a idade de xubilación, e nomeou reitor en funcións a Alfonso Barca Lozano (Carballo, 1948), catedrático de Psicoloxía Evolutiva e da Educación, que exerceu o cargo desde 01 de outubro de 2003 ao 8 de xaneiro de 2004.

Unha vez rematado o longo ciclo liderado por José Luis Meilán, accedeu á reitoría José María Barja Pérez (Mondoñedo, 1951), catedrático de Álxebra, primeiro reitor elixido por voto directo e ponderado do conxunto da comunidade universitaria en eleccións que tiveron lugar 02 de decembro de 2003. Será reelixido para un segundo mandato 04 de decembro de 2007. Nos seus oito anos de xestión produciuse a adaptación dos estudos universitarios ás directrices do Espazo Europeo de Educación Superior.

O actual reitor, Xosé Luís Armesto Barbeito (A Coruña, 1948), catedrático de Química Física, resultou elixido o 13 de decembro de 2011 e foi nomeado o 29 dese mesmo mes. A súa actuación está a coincidir cunha crise económica que limita considerablemente as posibilidades de desenvolvemento da UDC e do conxunto do sistema universitario público galego e español. Na inauguración do curso académico 2015-2016 anunciou que non se presentará á reelección.

A institución rexeuse nun primeiro momento polas Normas estatutarias provisionais da Universidade da Coruña e o Regulamento de réxime interno da Comisión de Goberno (Decreto 1/1990, do 11 de xaneiro). Os Estatutos foron elaborados polo Claustro Constituínte,

\footnotetext{
${ }^{12}$ Rubén Lois González, A Universidade (1960-1992) (Vigo: Xerais, 1994).

${ }^{13}$ José Luis Meilán Gil fixo un balance sobre a súa xestión en La Universidad de A Coruña en el sistema universitario (A Coruña: Instituto José Cornide de Estudios Coruñeses, 2004).
} 
que os aprobou na sesión que tivo lugar o 4 de febreiro de 1992, e referendados polo Decreto 253/1992, do 10 de setembro. Conseguiron o voto favorable do $85 \%$ dos claustrais.

No título preliminar dos seus primeiros Estatutos, a UDC establece como fins prioritarios a docencia, a investigación, a promoción do coñecemento nos seus diversos eidos e a extensión cultural; afirma a súa independencia respecto de grupos e poderes políticos, relixiosos, económicos ou sociais; subliña a vontade de colaborar coas universidades de Santiago de Compostela e Vigo no marco do Sistema Universitario Galego; recoñece a democracia como base do seu funcionamento, que se inspirará nos principios de igualdade, liberdade, participación e pluralismo; promete estar ao servizo do desenvolvemento intelectual e material da sociedade, da defensa do medio ambiente e da paz; e comprométese coa promoción da identidade cultural de Galicia, e especialmente da lingua galega, que será o seu vehículo normal de expresión.

Esta norma básica foi complementada por regulamentos que desenvolvían os seus apartados básicos, e tamén reformada en sucesivas ocasións. A reforma máis polémica tivo lugar no ano 2000, e consistiu en eliminar a limitación de mandatos do reitor e doutros órganos de gobernos de carácter unipersoal. En 2007, unha nova maioría claustral restableceu a limitación de mandatos a dous consecutivos.

O orzamentos multiplicáronse por 8,21 entre 1990 (13.991.562 euros) e 2014 (114.923.507), ou o que é o mesmo, o crecemento nominal anual medio durante este período foi do $9,17 \% .{ }^{14}$ Ora ben, se transformamos as unidades monetarias correntes en que veñen expresados os orzamentos anuais en unidades monetarias constantes -neste caso do ano 1990-, resulta que os orzamentos non se multiplicaron por 8,21, senón por 3,93 , cun crecemento real anual medio do $5,86 \%$.

Gráfico 1. Orzamentos en euros correntes e constantes (1990-2014)

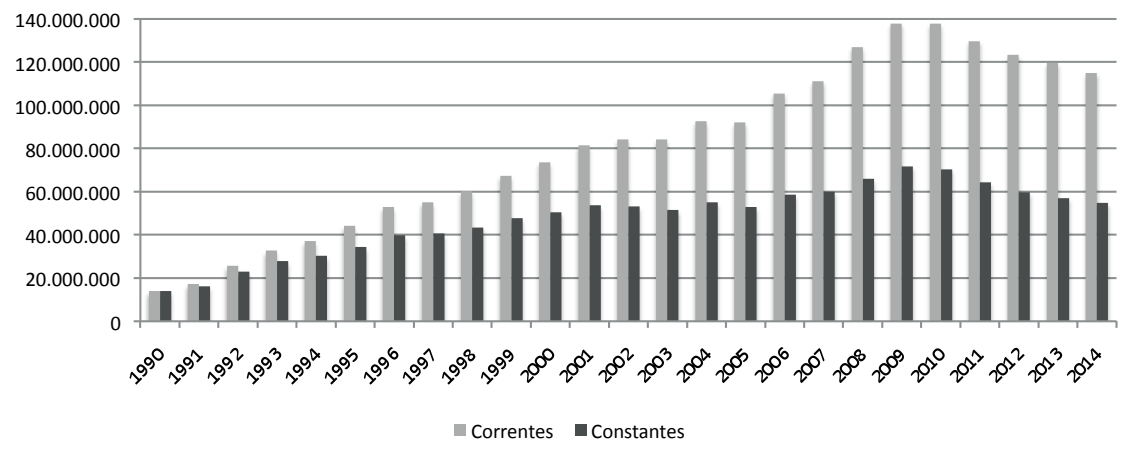

\footnotetext{
${ }^{14}$ Os datos sobre os orzamentos e a súa evolución fóronnos proporcionados pola Xerencia da UDC. Agradezo ao profesor Anxo Calvo Silvosa, decano da Facultade de Economía e Empresa, a análise que realizou deles para a exposición 25 anos de UDC. A universidade na Coruña e Ferrol.
} 
A tendencia ascendente mantense practicamente constante durante os primeiros vinte anos, mais a partir de 2009 invértese e prodúcese unha considerable perda de recursos: os 137.820.995 euros rexistrados nese ano convertéronse en 114.923.507 en 2014, cunha redución do $16,61 \%$. Estes recortes orzamentarios comprometen os esforzos realizados para a adaptación dos estudos ás esixencias derivadas da implantación do Espazo Europeo de Educación Superior e limitan as posibilidades de promover unha investigación de calidade, o que nunha institución nova como a UDC pode ter consecuencias especialmente críticas.

Os recursos conseguidos nos primeiros anos permitiron construír unha boa parte das actuais infraestruturas. Como sabemos, en 1989 xa estaban configurados os campus de Riazor, Serantes, A Zapateira e Bastiagueiro, pero as súas infraestruturas non eran en absoluto suficientes para dar resposta ás necesidades docentes e investigadoras da UDC, de modo que foi necesario dotarse de novos campus.

O campus máis extenso é o de Elviña, onde se construíron nunha primeira fase os edificios da Escola Técnica Superior de Enxeñaría de Camiños, Canais e Portos e da Facultade de Informática, inaugurados en 1993. As sedes das facultades de Dereito e de Humanidades -actualmente Ciencias da Educación- inauguráronse en febreiro de 1996, a de Socioloxía -compartida coa Facultade de Ciencias da Comunicación desde 2003-en decembro de 1998 e a de Ciencias Económicas e Empresariais —actualmente Economía e Empresa- en outubro de 2002. Tamén radican aquí outras infraestruturas: centros de investigación, instalacións deportivas, dependencias con usos preferentemente administrativos (Casa da Galería, Pavillón de Estudantes, Xoana Capdevielle) ou a escola infantil.

No tocante a Ferrol, o campus de Esteiro asentarase sobre os terreos e unha parte dos pavillóns do antigo Hospital de Mariña, cedido polo Ministerio de Defensa ao Concello e por este á UDC. Os edificios de cinco dos seis centros docentes que conforman o campus de Ferrol, construídos ao longo da década de 1990, están situados neste fermoso enclave, que conserva unha boa parte dos xardíns hospitalarios. Trátase da Facultade de Ciencias do Traballo, a Escola Politécnica Superior, a Facultade de Humanidades e Documentación e a Facultade de Enfermaría e Podoloxía. O campus conta, así mesmo, con edificios destinados a Vicerreitoría, Usos Administrativos, Apoio ao Estudo, Salón de Actos e Despachos, Centro de Investigacións Tecnolóxicas 1 e 2, Talleres Tecnolóxicos e Centro Cultural Universitario. ${ }^{15}$

O último campus que se configurou foi o de Oza, que tamén ten como antecedente máis inmediato un centro hospitalario, neste caso o Sanatorio Marítimo de Oza. ${ }^{16}$ O Edificio Universitario de Oza está destinado á Facultade de Fisioterapia, Escola Universitaria de Enfermaría -centro adscrito que ten a súa orixe na Escola de Axudantes Técnicos Sanitarios (1972)- e Facultade de Ciencias da Saúde

\footnotetext{
${ }^{15}$ José Ramón Soraluce Blond, O antigo Hospital de Esteiro. Campus Universitario de Ferrol (A Coruña: UDC, 1996). ${ }^{16}$ Pegadas da memoria. Imaxes do Sanatorio Marítimo de Oza desde 1910 ata a súa transformación en campus universitario (A Coruña: UDC, 2014).
} 
-esta facultade dispón tamén dun edificio específico situado nas proximidades do antigo sanatorio-. Outras dependencias aproveitadas para usos universitarios foron o Pavillón do Fortín, convertido en Instituto de Ciencias da Saúde, e a casa do conserxe, destinada ao decanato e a servizos de carácter administrativo.

Á marxe dos sete campus, fóronse acondicionando outras infraestruturas, entre as que salienta a sede da Reitoría, situada no antigo edificio da Maestranza; ${ }^{17}$ o Club Universitario, localizado no Dique Barrié de la Maza do porto coruñés e o Pazo de Lóngora (Oleiros). ${ }^{18}$

\section{Alumnado}

A matrícula en primeiro e segundo ciclo e grao aumentou de forma sistemática ata 0 curso 1999-2000. Os 14.268 alumnos e alumnas contabilizados en 1990 convertéranse en 27.119 nove anos máis tarde, cun incremento do 90\%. Desde o curso 2000-2001 a tendencia é, pola contra, sistematicamente descendente, de modo que en 2014-2015 había 16.797 matriculados, o que representa un descenso do 38\%. Esta dinámica obsérvase tanto en Ferrol como na Coruña. ${ }^{19}$

Gráfico 2. Matrícula en primeiro e segundo ciclo e grao (1990-2014)

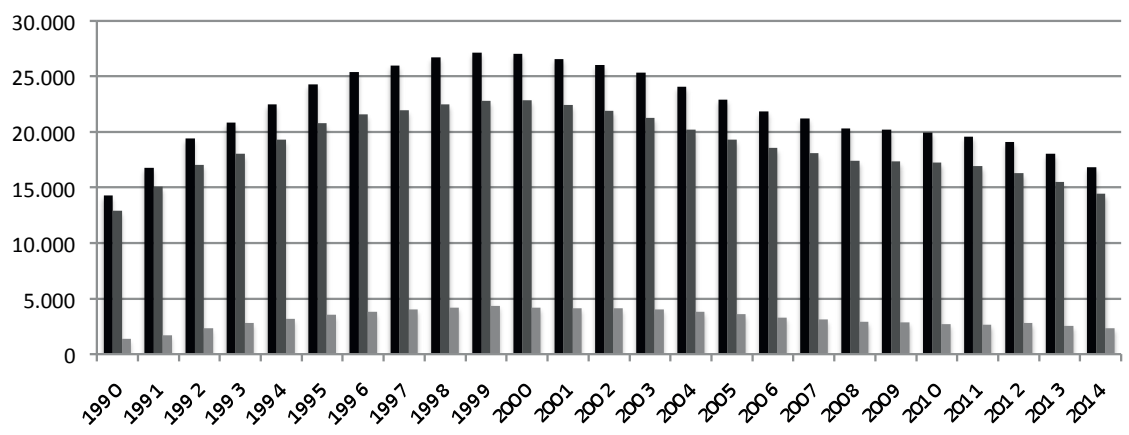

O peso relativo de Ferrol intensifícase ata 1999 e deseguido diminúe lixeiramente. En conxunto, e ao longo dos 25 anos considerados, a porcentaxe do seu alumnado é algo inferior ao $15 \%$.

Os factores que determinaron esta evolución foron de diversa índole (estrutura das titulacións, oferta de prazas, posibilidades que ofrece o mercado laboral etc.), pero a caída rexistrada no século XXI obedece a razóns fundamentalmente demográficas. A poboación

\footnotetext{
${ }^{17}$ José Ramón Soraluce Blond, Jesús Freire Pedreira e Gustavo Díaz García, A Antiga Maestranza de Artillería, Rectorado da Universidade da Coruña (A Coruña: UDC, 1996).

${ }^{18}$ Ángel Padín Panizo, Pazo de Lóngora (A Coruña: UDC, 2001).

${ }^{19}$ Os datos que serviron de base para a elaboración dos gráficos e cadros foron elaborados polos Servizos de Información e Estatística da UDC para a exposición 25 anos de UDC, ou ben proceden das memorias anuais do reitor e das estatísticas oficiais da UDC, que se poden consultar na súa páxina web. Agradezo a Ricardo Marqués Solla e a Juan José González Meizoso a súa eficaz e áxil colaboración.
} 
da provincia da Coruña comprendida entre os 18 e os 24 anos, ambos incluídos, ascendía en 1991 a 119.725 habitantes, e vinte anos máis tarde reducíase a 72.430. Malia que na derradeira década do pasado século o descenso é relativamente limitado, entre $2001 \mathrm{e}$ 2011 cífrase no $36,32 \%$, mentres que no conxunto de Galicia resulta bastante superior. Con esta evolución demográfica non existen condicións de posibilidade para o crecemento do alumnado universitario.

Se a partir do cambio de século o número de estudantes coruñeses de 18 a 24 anos matriculados na UDC descende, a súa porcentaxe respecto da poboación de referencia continúa aumentando, aínda que de forma moito menos intensa: 8,70\% (1991), 12,69\% (2001) e 12,93\% (2011). Parece, pois, que un dos principais obxectivos da Lei galega de universidades (1989), o de favorecer a extensión da educación superior, se está a conseguir en boa medida

Aínda que A Coruña é a provincia que achega o groso da matrícula -aproximadamente tres de cada catro estudantes-, as outras tres provincias galegas tamén están presentes, especialmente Pontevedra, polo seu potencial demográfico, e Lugo, pola súa proximidade xeográfica. Aproximadamente un $5 \%$ procede do resto do Estado e, en menor medida, do estranxeiro. Os valores non experimentan grandes cambios ao longo do tempo, aínda que se observa un lixeiro crecemento de persoas procedentes de fóra da provincia da Coruña, sobre todo entre 1995 e 2005.

Ciencias Sociais e Xurídicas e Enxeñaría e Arquitectura son os ámbitos científicos amplamente dominantes, superando o primeiro ao segundo ata o curso 2004-2005 e sucedendo o contrario, aínda que de forma menos intensa, a partir daquela. Entre ambos suman case 0 89\% do alumnado matriculado no período 1990-2013.

Entre 1998 -cando xa están consolidadas a maioría das titulacións-e 2013, as Ciencias Sociais e Xurídicas perden 4,94 puntos porcentuais, Artes e Humanidades 2,19 e Ciencias 1,36, mentres que Enxeñaría e Arquitectura gañan 4,89 e as Ciencias da Saúde 3,59.

Gráfico 3. Porcentaxe de alumnado por ámbitos de coñecemento (1998-2013)

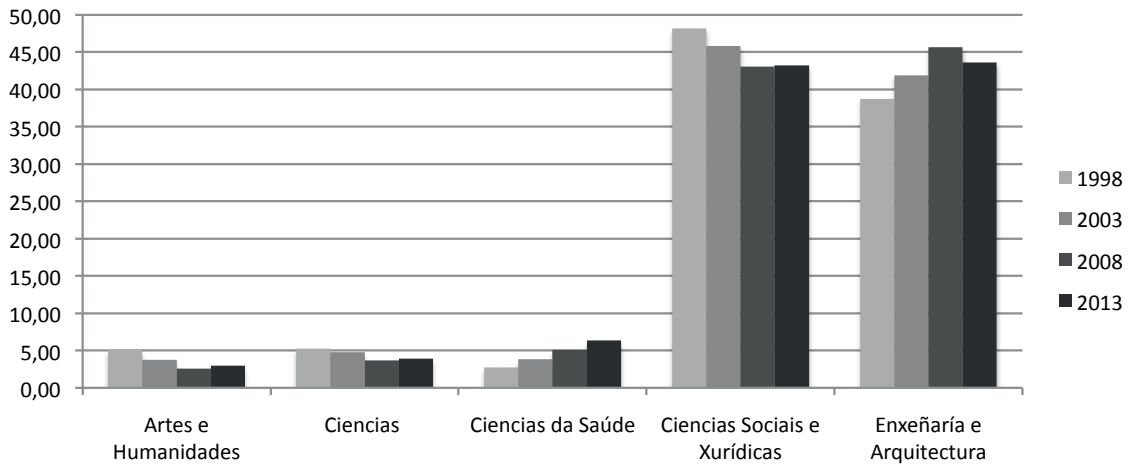

Atendendo ao conxunto da matrícula, non se observan diferenzas notables entre mulleres e homes. Se sumamos os efectivos de todos os cursos académicos, as mozas representan o 50,65\%, polo que o equilibrio é case perfecto. Existen, porén, importantes di- 
ferenzas entre os campus da Coruña e Ferrol. No primeiro, as mulleres superan os homes, mentres que no segundo a relación se inverte e adquire máis intensidade. Considerando a matrícula do conxunto da serie, nos centros coruñeses as rapazas representan o 52,77\% e nos ferroláns $038,71 \%$. A explicación da discrepancia radica no tipo de titulacións que se ofertan nunha e noutra cidade, e máis concretamente no predominio que ten en Ferrol 0 ámbito tecnolóxico.

Gráfico 4. Porcentaxe de mulleres sobre o total da matrícula (1995-2014)

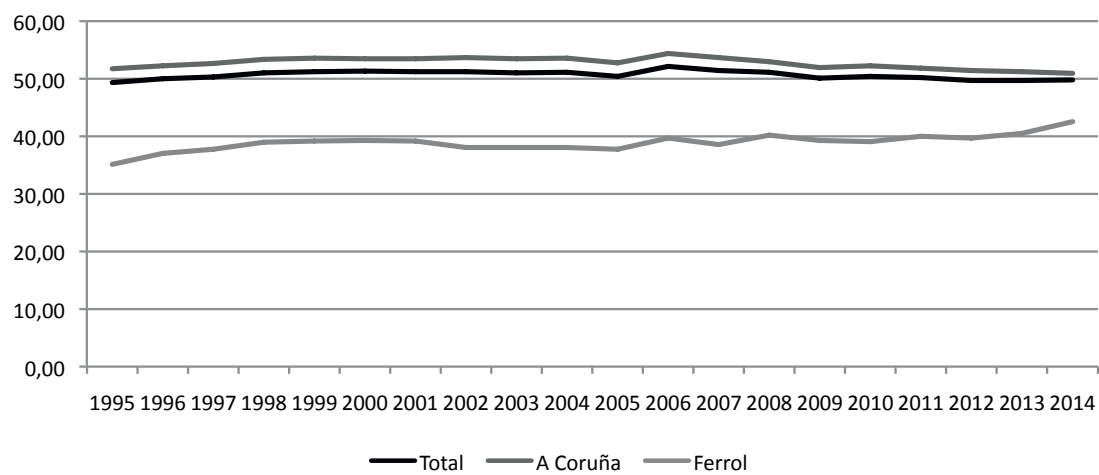

A máxima porcentaxe de mulleres matriculadas acádase no ámbito das Ciencias da Saúde, seguido de Artes e Humanidades, Ciencias, Ciencias Sociais e Xurídicas e Enxeñaría e Arquitectura. Entre 1995 e 2013 a "feminización" tende a descender en Artes e Humanidades, Ciencias e Ciencias da Saúde -especialmente en Fisioterapia- e aumenta levemente en Ciencias Sociais e Xurídicas debido ás facultades de Ciencias da Educación e de Ciencias do Traballo, pois nas restantes redúcese. En Enxeñaría e Arquitectura, onde existía unha ampla marxe de crecemento, a presenza das mulleres incrementouse só en tres puntos, que se multiplicaron por catro $(12,88)$ na Escola Técnica Superior de Arquitectura; na Facultade de Informática obsérvase o proceso inverso: a "masculinización" aumentou 8,88 puntos ata situarse no $84,91 \%$.

Gráfico 5. Porcentaxe de mulleres matriculadas por ámbito de coñecemento (1995 e 2013)

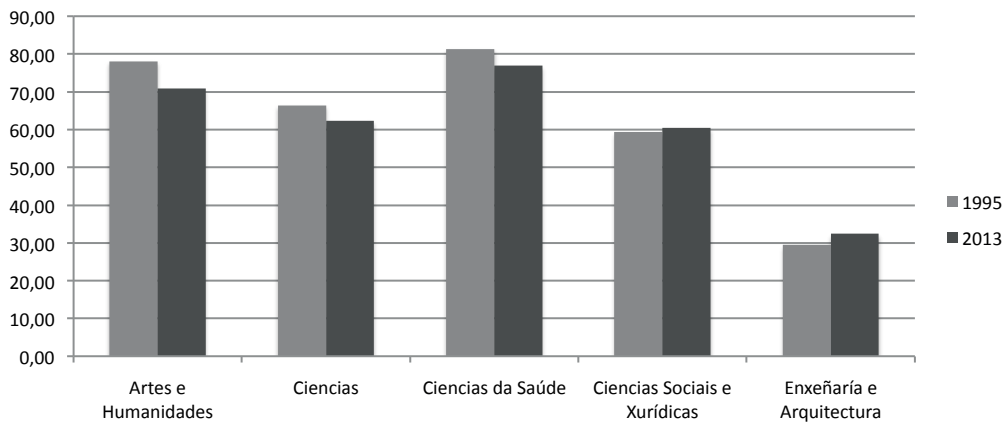


Desde 1991 a 2014 expedíronse 62.172 títulos correspondentes a estudos de diplomatura, licenciatura, enxeñaría e arquitectura, a unha media de 2.590 por ano. A medida que se consolidan as novas titulacións, e coincidindo co importante crecemento da matrícula na última década do pasado século, tamén aumenta considerablemente o número de persoas tituladas, mais desde comezos do século xxı obsérvanse frecuentes oscilacións, que obedecen tanto á diminución da matrícula como a factores de carácter académico.

Gráfico 6. Número de persoas tituladas (1991-2014)

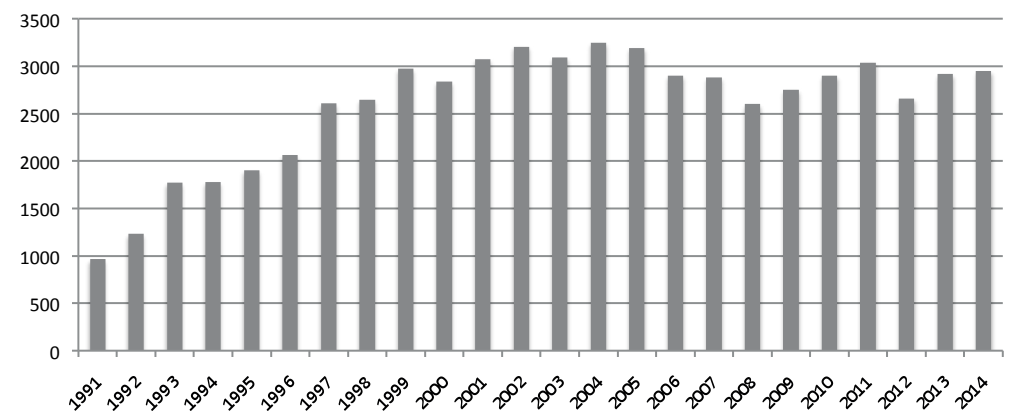

De cada 100 persoas tituladas, aproximadamente 54 fixérono no ámbito das Ciencias Sociais e Xurídicas, 31 en Enxeñaría e Arquitectura, 8 en Ciencias da Saúde, 4 en Artes e Humanidades e 3 en Ciencias. Algo máis do $58 \%$ das persoas tituladas son mulleres. A porcentaxe de tituladas é sensiblemente superior á de titulados en todos os ámbitos, se exceptuamos o tecnolóxico.

A este volume de persoas matriculadas e tituladas habería que sumar as correspondentes aos novos mestrados oficiais, estudos de doutoramento, estudos propios da UDC e ao Curso de Aptitude Pedagóxica. Neste último matriculáronse 6.484 persoas entre 1999 e 2008.

\section{Profesorado}

A incorporación de persoal docente e investigador (PDI) foi constante desde a creación da UDC ata 2010. Nos catro anos seguintes invértese a tendencia debido ás limitacións orzamentarias e ás restricións administrativas, de modo que os efectivos se reducen en 50.

A evolución é similar na Coruña e Ferrol: no primeiro caso a porcentaxe de crecemento entre 1995 e 2014 é do 66,48\% e no segundo do 63,82\%. O peso do profesorado de Ferrol na UDC ao longo de toda a serie supera levemente o $19 \%$.

O intenso crecemento inicial do PDI -desde 1990 a 1997 duplícase- débese á creación de novos centros e á implantación de novas titulacións, así como á incorporación dos segundos ciclos dalgunhas das titulacións existentes no antigo Colexio Universitario.

A actual diminución do profesorado prodúcese nun momento en que a universidade necesitaría aumentar os seus efectivos, pois se algo require a adaptación ao Espazo Euro- 
peo de Educación Superior -e en definitiva, un ensino de calidade- é unha atención máis individualizada do alumnado por parte do profesorado.

Gráfico 7. Profesorado (1990-2014)

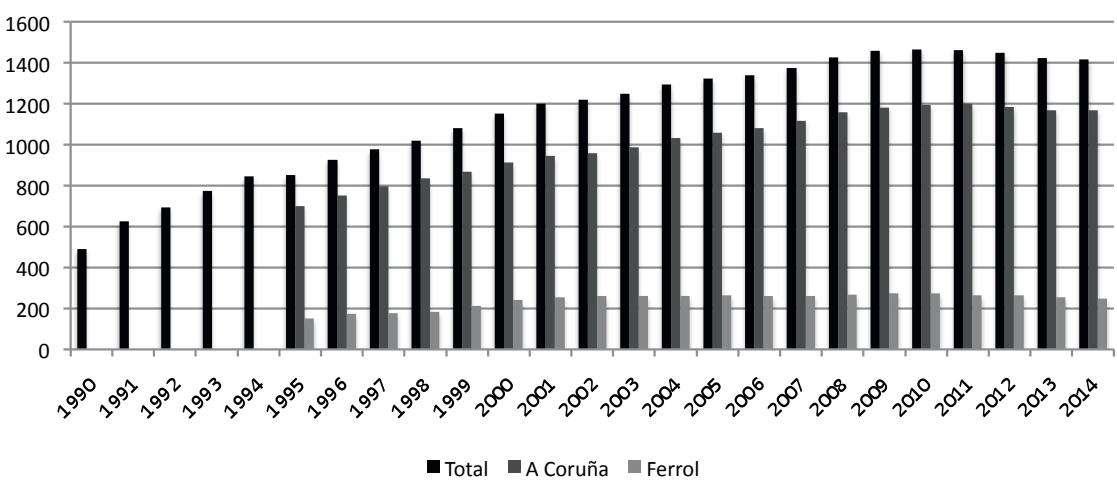

As mulleres supuñan o $28,49 \%$ do profesorado en 1995 e o 36,94\% en 2014, correspondendo a maior parte do crecemento á última década. Estas porcentaxes contrastan coas que ofrece 0 alumnado, malia que no futuro seguramente seguirán aumentando, aínda que non sexa máis que por mor da renovación xeracional: entre 2010 e 2014 perdéronse 71 profesores e gañáronse 21 profesoras.

A distribución porcentual do profesorado por grupos de idade evidencia unha caída notable e progresiva dos menores de 40 anos e unha ascensión non menos notable e progresiva dos maiores de 50. Só o grupo de 40-49 anos ten un peso relativamente estable. 0 máis preocupante son as cifras dos menores de 30 anos: catro profesores e 12 profesoras en 2013. O envellecemento do profesorado é un proceso natural, mentres que a falta de renovación dos seus efectivos é un problema social: pon de manifesto que non existe a necesaria conciencia da necesidade de apostar pola formación, a investigación, a innovación e o desenvolvemento. En definitiva, polo futuro.

Gráfico 8. Porcentaxe de profesorado por grupos de idade (1995-2013)

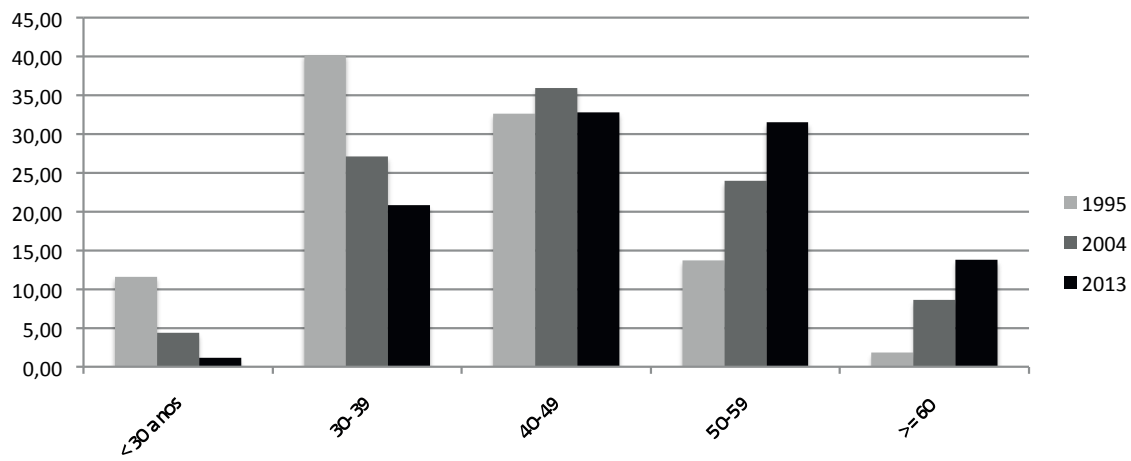


Nos catro primeiros anos predominaba a condición de contratado sobre a de funcionario, mais a partir de 1994 sucede o contrario. A funcionarización intensifícase ata 2003 $(67,87 \%)$ e descende a continuación, coincidindo coa implantación de novos sistemas para poder acceder á función docente (habilitación primeiro e acreditación máis tarde). 0 profesorado contratado ascendía ao 46,68\% en 2011.

Gráfico 9. Profesorado funcionario e contratado (1990-2014)

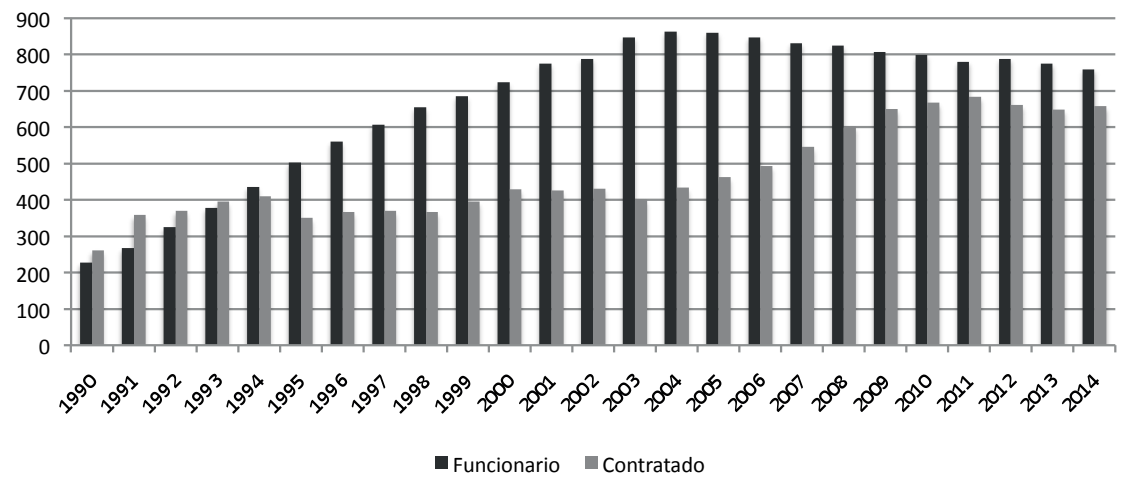

A evolución das catro categorías básicas de profesorado funcionario recollidas na Lei de reforma universitaria (LRU) permite observar que o profesorado titular de escola universitaria (TEU), maioritario ata 1994, en sintonía co predominio que tiñan nun primeiro momento as escolas universitarias, entra nunha fase de declive a partir de 2003 , e que os catedráticos de escola universitaria (CEU) foron sempre os menos numerosos. Un e outro corpo docente están en extinción desde 2007. Os titulares de universidade (TU) constitúen a categoría central do funcionariado a partir de 1995, e a súa relación cos catedráticos de universidade (CU) tende a ser de 3 a 1 desde ese mesmo ano.

Gráfico 10. Categorías de profesorado funcionario (1990-2014)

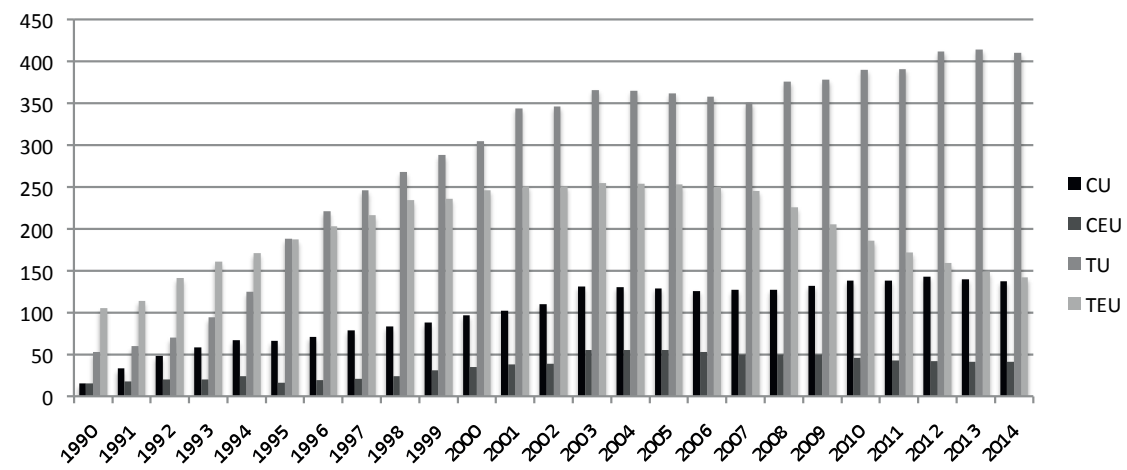


A estas categorías habería que unir, ademais doutras con menos peso, o profesorado específico da Escola Superior da Mariña Civil e do Instituto Nacional de Educación Física. No conxunto da serie representan aproximadamente $07 \%$.

A Lei orgánica de universidades (2001) conserva as categorías da LRU para o profesorado funcionario e introduce novas figuras de profesorado contratado: axudante doutor $(A D)$, contratado doutor $(C D)$ e colaborador $(C)$, que se unen ás previstas na LRU: axudante (AX), asociado (AS) e visitante. 0 profesorado colaborador restrinxiuse ás diplomaturas desde 2007 e en 2013 converteuse nunha figura en extinción.

O profesorado asociado, incluído o do ámbito de Ciencias da Saúde, constituíu historicamente 0 groso da contratación. Acadou a súa máxima cota no curso 2000-2001 $(83,44 \%)$ e a mínima no 2013-2014 (30,61\%). Entre 2004 e 2014 destaca o incremento do profesorado contratado doutor -os 17 iniciais convertéronse en 200-, que se equipara por primeira vez co asociado no curso académico 2014-2015. En sentido contrario, resulta especialmente preocupante a práctica desaparición dos axudantes, reducidos actualmente a tres, fronte aos 56 que había en 2006-2007. Esta desaparición, unida ao aumento do profesorado contratado interino de substitución (CIS) e ás crecentes dificultades de acceso ás categorías funcionariais, poñen de manifesto a incidencia que a crise económica e os recortes orzamentarios están a ter na universidade.

Gráfico 11. Categorías de profesorado contratado (2004-2014)

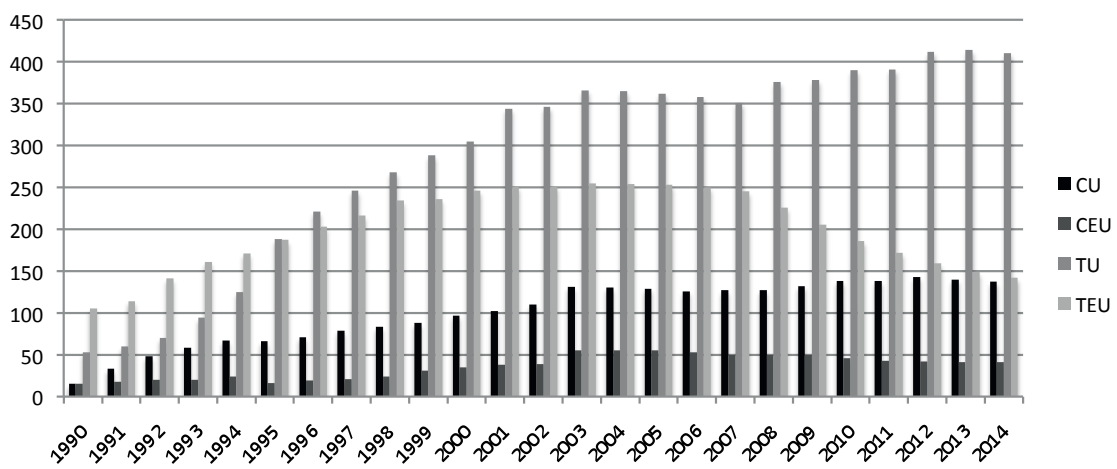

0 profesorado doutor -condición que confire a capacidade investigadora- con vinculación permanente á universidade (CU, CEU, TU e CD) reducíase a algo menos do $17 \%$ no momento de se crear a UDC. O peso das escolas universitarias e dos centros de carácter técnico, nutridos preferentemente de profesorado asociado e titular de escola, explica esta circunstancia. A tendencia da porcentaxe é claramente ascendente -os máximos incrementos rexistráronse en 1995 e 2008-, mais haberá que agardar a 2011 para que se supere a barreira do $50 \%$. A evolución da actividade investigadora na UDC resulta indisociable deste parámetro. 
Gráfico 12. Porcentaxe de profesorado doutor con vinculación permanente á universidade $(1990-2014)$

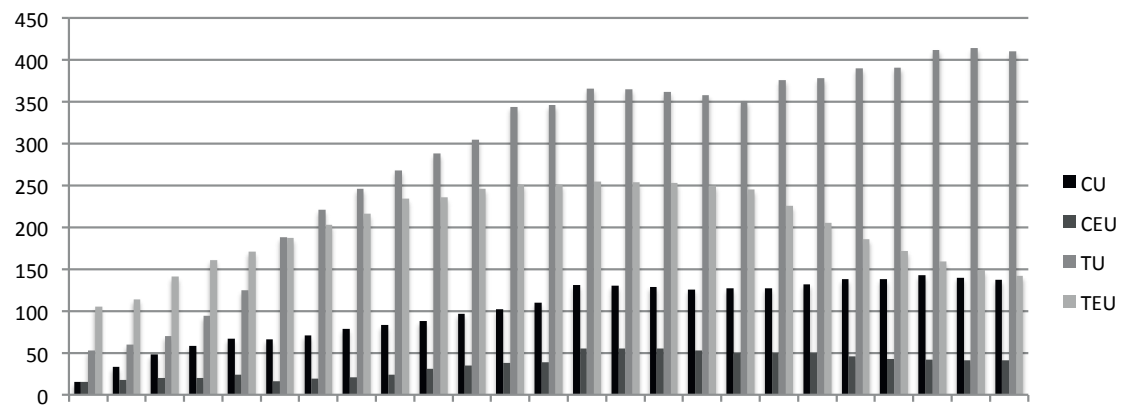

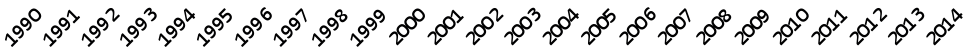

\section{Persoal de administración e servizos}

En 1995 había 324 persoas traballando na administración e nos diferentes servizos da UDC e 757 en 2014, polo que se produciu un incremento de algo máis do 133\%. A suma de efectivos mantívose constante ata 2010 e acadou a súa máxima intensidade en 19992001 e 2004-2006. A partir de 2010 perdéronse 34 persoas, por máis que no último curso se gañaron seis. O peso de Ferrol no conxunto da serie aproxímase ao 15\%.

Gráfico 13. Persoal de administración e servizos (1995-2014)

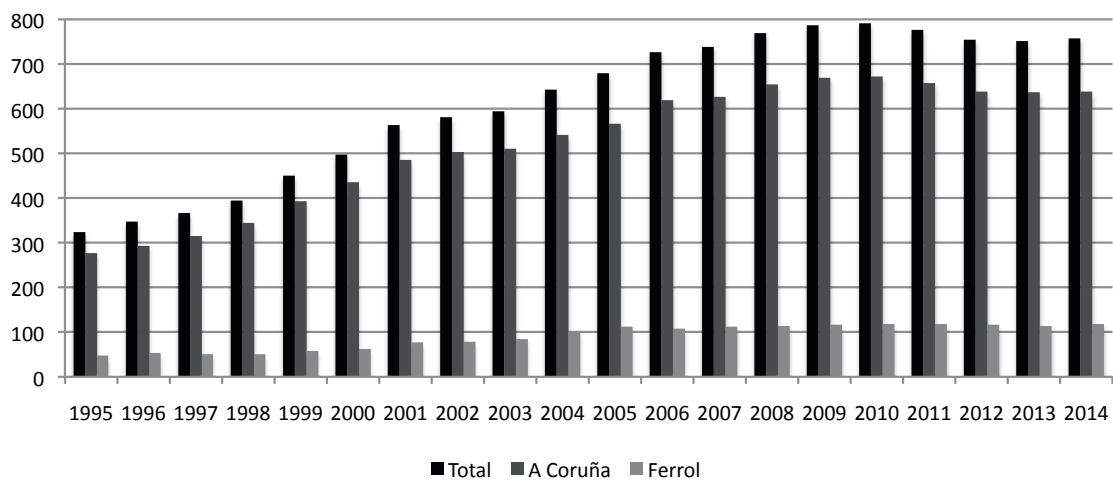

Prescindindo do persoal eventual e doutras categorías, que teñen unha presenza reducida -inferior ao 4\% sumando os efectivos de todos os anos-, e centrándonos no persoal funcionario e contratado, obsérvase que o primeiro supera por primeira vez o segundo en 2004, cun aumento interanual de 11 puntos. En 2013 aprobouse unha nova relación de postos de traballo para a funcionarización do persoal contratado, o que supuxo un avance de case 27 puntos. Se en 1995 o funcionariado representaba o 36,52\%, en 2014 representa 0 88,46\%. Está previsto que en 2015 se complete o proceso de funcionarización acordado coas organizacións sindicais. 
Gráfico 14. Persoal de administración e servizos funcionario e contratado (1995-2014)

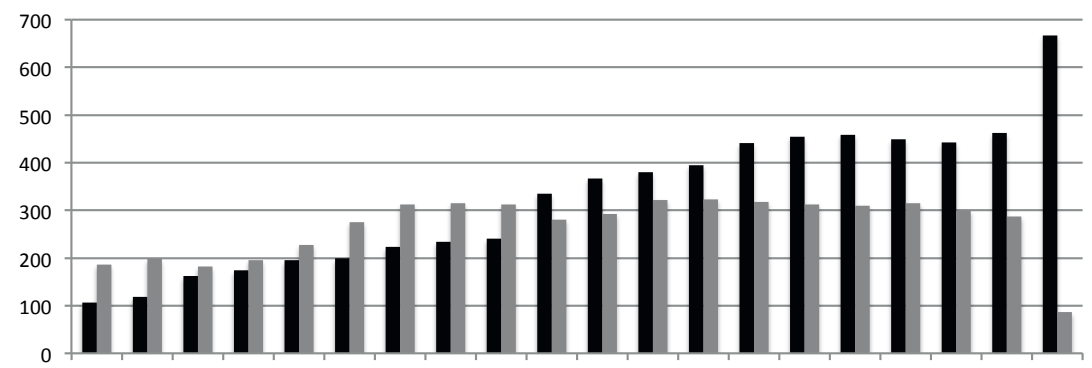

19951996199719981999200020012002200320042005200620072008200920102011201220132014

- Funcionario Contratado

O número de mulleres supera sempre o de homes, oscilando o seu peso entre 0 55,23\% (1997) e o 63,73\% (2005). Entre o funcionariado, tres de cada catro membros do PAS son mulleres, mentres que no persoal contratado a porcentaxe de homes se aproxima ao $57 \%$.

En 1995 había un membro do PAS por cada 2,63 integrantes do profesorado, e en 2014 un por cada 1,85. Nos primeiros anos a relación conserva os valores iniciais, pero desde comezos do século xx a proporción descende e tende a estabilizarse ao redor dos valores actuais.

\section{Gráfico 15. Relación profesorado/PAS (1995-2014)}

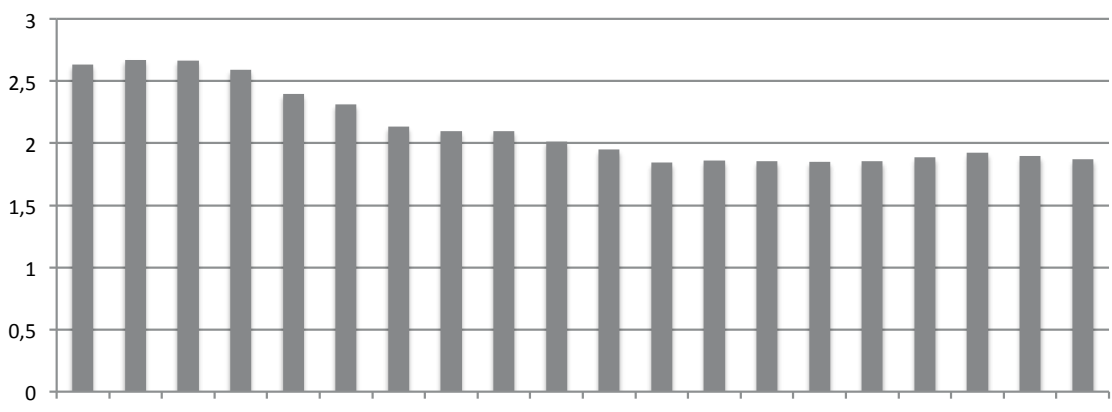

19951996199719981999200020012002200320042005200620072008200920102011201220132014

Aproximadamente un de cada tres membros do PAS traballa en labores de xestión académica e de conserxaría e mantemento dos centros. As outras cinco categorías cun peso próximo ou superior ao 10\% son bibliotecas, investigación, informática e comunicacións, xestión económica e secretaría administrativa e xerencia. Estes sete ámbitos laborais suman $082,83 \%$ dos efectivos. 
Táboa 1. Distribución funcional do PAS (2015)

\section{Distribución funcional}

\begin{tabular}{|l|c|c|}
\hline \multicolumn{1}{|c|}{ Área } & Número & $\%$ \\
\hline Xestión académica & 127 & 16,78 \\
\hline Conserxaría e mantemento de centros & 117 & 15,46 \\
\hline Bibliotecas & 105 & 13,87 \\
\hline Investigación & 81 & 10,70 \\
\hline Informática e comunicacións & 72 & 9,51 \\
\hline Xestión económica & 64 & 8,45 \\
\hline Secretaría administrativa e xerencia & 61 & 8,06 \\
\hline Estudantes e extensión universitaria & 34 & 4,49 \\
\hline Recursos humanos & 28 & 3,70 \\
\hline Gabinete técnico e apoio xurídico & 19 & 2,51 \\
\hline Arquitectura, urbanismo e equipamentos & 13 & 1,72 \\
\hline Distribución e rexistro & 13 & 1,72 \\
\hline Relacións internacionais e cooperación & 12 & 1,59 \\
\hline Innovación e calidade na docencia & 8 & 1,06 \\
\hline Normalización lingüística & 3 & 0,40 \\
\hline Total & 757 & \\
\hline
\end{tabular}

\section{Docencia}

A Universidade da Coruña ofrecía 45 titulacións no curso 2000-2001, das que 12 correspondían a licenciaturas, 18 a diplomaturas, catro a enxeñarías, sete a enxeñarías técnicas, unha a Arquitectura e outra a Arquitectura Técnica. A implantación do Espazo Europeo de Educación Superior (EEES) supuxo a transformación de todas as titulacións en graos, a non ser as enxeñarías superiores, que se transformaron en graos máis mestrados.

O ensino de grao ten como finalidade a obtención por parte do estudante dunha formación xeral, nunha ou varias disciplinas, orientada á preparación para o exercicio de actividades de carácter profesional. A maioría das titulacións están organizadas en catro cursos, e o número de créditos ECTS que se deben superar para graduarse é de 240.

A principal característica distintiva do novo modelo radica, no que respecta á metodoloxía didáctica, na pretensión de promover o traballo autónomo do alumnado, ao que se quere implicar de forma máis activa no proceso de aprendizaxe, e nunha atención máis individualizada dos estudantes por parte do profesorado. Neste sentido, as clases expositivas son complementadas por outras de carácter interactivo e, cando existe suficiente capacidade docente, por clases titoriais. Outras novidades consisten na obrigatoriedade 
de realizar e defender un traballo de fin de grao e na potenciación de prácticas externas orientadas a familiarizar os estudantes co mundo profesional.

No curso 2014-2015 impartíanse 37 titulacións de grao -dúas delas con docencia en Ferrol e na Coruña-, das que cinco eran de Artes e Humanidades, dúas de Ciencias, cinco de Ciencias da Saúde, 12 de Ciencias Sociais e Xurídicas e 13 de Enxeñaría e Arquitectura. A esta oferta engadíanse catro programas que permiten cursar de forma simultánea dous graos: Bioloxía e Química; Turismo e Ciencias Empresariais; Administración e Dirección de Empresas e Dereito, e Ciencias Empresariais e Arquitectura Técnica.

Destas titulacións, 11 son únicas no Sistema Universitario Galego, case todas do campo tecnolóxico; 13 habilitan para o exercicio dunha profesión e tres constitúen condición necesaria para a obtención do título profesional.

\section{Táboa 2. Estudos de Grao}

\begin{tabular}{|c|c|}
\hline Artes e Humanidades & Educación Infantil (2) \\
\hline Español: Estudos Lingüísticos e Literarios & Educación Primaria (2) \\
\hline Galego e Portugués: Estudos Lingüísticos e Literarios & Educación Social \\
\hline Humanidades (Ferrol) & Relacións Labo. e Rec. Humanos (A Coruña e Ferrol) \\
\hline Información e Documentación (Ferrol) & Socioloxía (1) \\
\hline Inglés: Estudos Lingüísticos e Literarios & Turismo \\
\hline Ciencias & Turismo e Ciencias Empresariais \\
\hline Bioloxía & Administración e Dirección de Empresas e Dereito \\
\hline Química & Enxeñaría e Arquitectura \\
\hline Bioloxía e Química & Arquitectura $(1,2)$ \\
\hline Ciencias da Saúde & Arquitectura Técnica $(1,2)$ \\
\hline Enfermaría (A Coruña e Ferrol) (2) & Enx. de Deseño Ind. e Desen. do Produto (Ferrol) (1) \\
\hline Fisioterapia (2) & Enxeñaría de Obras Públicas $(1,2)$ \\
\hline Logopedia $(1,2)$ & Enxeñaría Eléctrica (Ferrol) (2) \\
\hline Podoloxía (Ferrol) (2) & Enx. Electrónica Industrial e Automática (Ferrol) (2) \\
\hline Terapia Ocupacional $(1,2)$ & Enxeñaría en Tecnoloxías Industriais (Ferrol) \\
\hline Ciencias Sociais e Xurídicas & Enxeñaría Informática \\
\hline Administración e Dirección de Empresas & Enxeñaría Mecánica (Ferrol) (2) \\
\hline Ciencias da Actividade Física e do Deporte & Enxeñaría Naval e Oceánica (Ferrol) $(1,2)$ \\
\hline Ciencias Empresariais & Náutica e Transporte Marítimo $(1,3)$ \\
\hline Comunicación Audiovisual & Tecnoloxía da Enxeñaría Civil (1) \\
\hline Dereito & Tecnoloxías Mariñas $(1,3)$ \\
\hline Economía & Ciencias Empresariais e Arquitectura Técnica \\
\hline
\end{tabular}

(1) Titulación única no Sistema Universitario Galego; (2) Habilita para profesión regulada; (3) Condición de acceso para a obtención do título profesional. 
Os mestrados teñen como finalidade a adquisición por parte do estudante dunha formación avanzada, de carácter especializado ou multidisciplinar, orientada á especialización académica ou profesional, ou ben a promover a iniciación en tarefas investigadoras.

Aínda que a carga docente pode oscilar entre 60 e 120 créditos ECTS, a maioría ten 60, algúns 90 e só o de Enxeñaría de Camiños, Canais e Portos chega aos 120. Como tamén sucede nos graos, é preciso elaborar e defender un traballo de fin de mestrado e, no seu caso, realizar as prácticas externas.

No curso 2014-2015 ofrecéronse 43 mestrados: tres en Artes e Humanidades, sete en Ciencias, tres en Ciencias da Saúde, 15 en Ciencias Sociais e Xurídicas e 15 en Enxeñaría e Arquitectura. Neste último ámbito existen dous máis en proceso de modificación. Un dos mestrados, o de Profesorado, ten oito especialidades.

Unha boa parte dos títulos, concretamente 17, ten carácter interuniversitario, catro habilitan para o exercicio dunha profesión e tres constitúen condición necesaria para a adquisición do título profesional.

\section{Táboa 3. Estudos de Mestrado}

\begin{tabular}{|c|c|}
\hline Artes e Humanidades & Migracións Internacionais (1) \\
\hline Estudos Ingleses Avanzados e as súas Aplicacións (1) & Plani. e Xest. de Destinos e Novos Produtos Turísticos \\
\hline Lingüística Aplicada (1) & Prevención de Riscos Laborais e Riscos Comúns (Ferrol) \\
\hline Literatura, Cultura e Diversidade (1) & Profesorado de ESO e Bac., FP e Ens. de Idiomas (2) \\
\hline Ciencias & Psicoloxía Aplicada \\
\hline Acuicultura (1) & Psicopedagoxía \\
\hline Bioloxía Mariña (1) & Xestión e Dirección Laboral (Ferrol) (1) \\
\hline Bioloxía Molecular, Celular e Xenética (1) & Enxeñaría e Arquitectura \\
\hline Biotecnoloxía Avanzada (1) & Arquitectura da Paisaxe Juana de Vega (4) \\
\hline Ciencias, Tecnoloxías e Xestión Ambiental & Computación de Altas Prestacións (1) \\
\hline Neurociencia (1) & Dirección Integrada de Proxectos (1) \\
\hline Técnicas Estatísticas (1) & Enxeñaría da Auga (1) \\
\hline Ciencias da Saúde & Enxeñaría Industrial (Ferrol) (2) \\
\hline Asistencia e Investigación Sanitaria & Enxeñaría Informática \\
\hline Intervención na Discapacidade e na Dependencia & Enxeñaría Mariña (3) \\
\hline Xerontoloxía (1) & Enxeñaría Náutica e Transporte Marítimo (3) \\
\hline Ciencias Sociais e Xurídicas & Enxeñaría Naval e Oceánica (Ferrol) (2) \\
\hline Asesoramento Xurídico Empresarial & Enxeñería de Camiños, Canais e Portos (2) \\
\hline Avogacía (3) & Fotónica e Tecnoloxías do Láser (Ferrol) \\
\hline Banca e Finanzas & Investigación en Enxeñaría Civil \\
\hline Contabilidade Superior e Auditoría de Contas & Matemática Industrial (1) \\
\hline Dereito: Estudos da Unión Europea & Materiais Complexos: Análise Térmica e Reoloxía (Ferrol) (1) \\
\hline Dirección e Administración de Empresas & Rehabilitación Arquitectónica \\
\hline Dirección, Xest. e Inno. de Instit. Escol. e Socio-educativas & Tecnoloxías de Edificación Sostible \\
\hline Estudos Avan. sobre Ling., Comun. e as súas Patoloxías (1) & Urbanismo: Plans e Proxectos. Do Territ. á Cidade (4) \\
\hline
\end{tabular}


A Escola Internacional de Doutoramento da UDC (EIDUDC), creada no ano 2013, é o centro que asume a organización, planificación, xestión, supervisión e seguimento da oferta global de actividades propias do doutoramento.

No curso académico 2014-2015 a UDC tiña 34 programas de doutoramento organizados segundo o Real decreto 99/2011: cinco en Artes e Humanidades, nove en Ciencias, tres en Ciencias da Saúde, seis en Ciencias Sociais e Xurídicas e 11 en Enxeñaría e Arquitectura. Destes programas, 22 son interuniversitarios, tres internacionais e 10 proceden de antigos programas de doutoramento con mención á excelencia.

A diferenza das regulacións anteriores, o Real decreto 99/2011 non recolle estudos específicos de doutoramento, aínda que si una serie de actividades de carácter formativo, e pretende centrar a actividade dos estudantes de doutoramento na realización da tese.

Táboa 4. Programas de Doutoramento

\begin{tabular}{|l|l|}
\hline \multicolumn{1}{|c|}{ Artes e Humanidades } & \multicolumn{1}{|c|}{ Ciencias Sociais e Xurídicas } \\
\hline Estudos Ingleses Avanz.: Lingüíst., Literat. e Cult. (1) & Análise Económica e Estratexia Empresarial (1) \\
\hline Estudos Lingüísticos (1) & Ciencias do Deporte, Educ. Física e Acti. Física Saud. \\
\hline Estudos Literarios (1) & Dereito \\
\hline Lóxica e Filosofía da Ciencia (Ferrol) (1) & Dereito Administrativo Iberoamericano (1, 2) \\
\hline Sociedade do Coñecemento (Ferrol) & Desenvolve. Psicolóxico, Aprendizaxe e Saúde (1) \\
\hline \multicolumn{1}{|c|}{ Ciencias } & Equidade e Innovación en Educación (1) \\
\hline Do Mar (1, 2) & \multicolumn{1}{|c|}{ Enxeñaría e Arquitectura } \\
\hline Bioloxía Celular e Molecular (3) & Arquitectura e Urbanismo \\
\hline Biotecnoloxía Avanzada (1) & Computación \\
\hline Ciencia e Tecnoloxía Ambiental (3) & Enerxía e Propulsión Mariña (1) \\
\hline Estatística e Investigación Operativa (1,3) & Enxeñaría Civil (3) \\
\hline Física Aplicada (1, 3) & Enxeñaría Naval e Industrial (Ferrol) \\
\hline Investigación Agraria e Forestal (1) & Investigación en Tecnoloxías da Información (1, 3) \\
\hline Química Ambiental e Fundamental (3) & Láser, Fotónica e Visión (Ferrol) (1) \\
\hline Ciencias da Saúde & Mét. Matemát. e Simul. Num. en Enx. e CC.AA (1,3) \\
\hline Niencias da Saúde & Tecnoloxías da Información (1,3) \\
\hline Nanomedicina (1) & Tecnoloxías da Información e as Comunicacións (3) \\
\hline Neurociencias (1) & Tecnol. da Infor. e das Comu. en Redes Móbiles (1, 3) \\
\hline
\end{tabular}

(1) Interuniversitario; (2) Internacional; (3) Procedente dun programa con mención cara á excelencia.

A UDC ofrece tamén estudos propios de posgrao, que conducen á obtención de títulos e diplomas exclusivos desta universidade. Pretenden dar resposta ás necesidades de formación específica tanto de persoas que xa remataron os seus estudos como de profesionais con certa experiencia no mundo laboral. Atendendo á carga lectiva, requisitos 
de acceso e certificación que se expide, clasifícanse en tres categorías: mestrados universitarios, cursos de especialización e cursos de formación específica de posgrao.

Ademais dos estudos de grao, mestrado, doutoramento e propios, prográmase unha gran variedade de cursos e outras actividades de carácter formativo organizadas por diversas instancias, como é o caso da Aula de Formación Informática, o Centro Universitario de Formación e Innovación Educativa e o Centro de Linguas.

\section{Investigación e transferencia}

As universidades son institucións de carácter docente e investigador. Sen a docencia simplemente non existirían como tales, mais as avaliacións e clasificacións a que son sometidas realízanse basicamente en función da investigación. 0 mesmo acontece co seu financiamento, que cada vez depende máis da actividade investigadora. A Universidade da Coruña partía dunha situación moi precaria, pois a maioría dos seus centros eran escolas universitarias, cuxo profesorado se dedicaba fundamentalmente á docencia.

Referirémonos en primeiro lugar ás estruturas que serven de soporte á actividade investigadora e logo a algúns indicadores que poñan de manifesto a súa evolución nos primeiros 25 anos de vida da institución.

\section{Estruturas}

a) Departamentos, institutos, grupos e unidades de investigación

Os departamentos son as unidades de docencia e investigación encargadas de coordinar 0 ensino nunha ou máis áreas de coñecemento. 0 seu número ascende a 43 , dos que 16 corresponden ao ámbito tecnolóxico, 14 ao xurídico-social, seis ao científico, catro ao humanístico e tres ao sanitario.

Os institutos son centros dedicados á investigación científica e técnica ou á creación artística, así como á docencia especializada de posgrao ou de doutoramento. Na actualidade son oito.

Nos últimos anos as competencias en materia de investigación foron transferidas en boa medida aos grupos e unidades de investigación. Os primeiros constitúen a estrutura básica para a organización e a xestión da actividade investigadora. Son o resultado da asociación voluntaria de persoal investigador que comparte unhas determinadas liñas de investigación, desenvolvemento e innovación. 0 seu número cífrase en 121, dos que 22 foron catalogados pola Xunta de Galicia como grupos de referencia competitiva e 21 como grupos con potencial de crecemento. As unidades defínense como unha agrupación de persoal investigador de menor tamaño que os grupos e con actividade constatable nos últimos cinco anos. Actualmente suman 30.

No catálogo da UDC están rexistrados máis de 1.100 investigadores e investigadoras, cuxa actividade é avaliada desde 2012 por unha axencia externa, a Agencia Nacional de Evaluación y Prospectiva (ANEP). 
b) Parque científico-tecnolóxico

Está formado por catro centros: CICA, CITEEC e CITIC (campus de Elviña) e CIT (campus de Esteiro), aos que están adscritos diferentes grupos de investigación. A través destes centros promóvense as relacións directas entre universidade e empresa.

O Centro de Investigacións Científicas Avanzadas (CICA) está integrado por investigadores e investigadoras que traballan no ámbito da química, a bioloxía e as ciencias ambientais. Os seus obxectivos básicos son o desenvolvemento de proxectos de investigación financiados por axencias públicas ou privadas e por empresas, a transferencia e a difusión dos resultados da investigación e a formación de persoal investigador.

O Centro de Investigacións Tecnolóxicas (CIT) acolle seis grupos de investigación que traballan en diferentes ámbitos das tecnoloxías industriais. Está principalmente orientado á colaboración coas empresas, ás que ofrece diversos servizos: desenvolvemento de proxectos de investigación, transferencia tecnolóxica e de coñecemento, asistencia técnica, realización de ensaios e formación e asistencia en materia de vixilancia tecnolóxica.

O Centro de Innovación Tecnolóxica en Edificación e Enxeñaría Civil (CITEEC) ten como obxectivo promover a investigación de base e aplicada, e asesorar empresas e institucións en materia de construción, tanto no que respecta á edificación como á enxeñaría civil. Conta con laboratorios de Construción, Enxeñaría Sanitaria e Ambiental, Hidráulica, Portos e Costas e Túnel de Vento.

O Centro de Investigación en Tecnoloxías da Información e as Comunicacións (CITIC) é un lugar de encontro entre o persoal investigador dos departamentos de I+D dalgunhas das máis importantes empresas do sector das tecnoloxías da información e as comunicacións (TIC) e o persoal da UDC. Pretende potenciar a investigación, o desenvolvemento e a innovación nas TIC, fomentar a transferencia tecnolóxica e de resultados ás empresas e á sociedade, e estimular a capacidade de xerar emprego do sector TIC.

c) Servizos de Apoio á Investigación (SAI)

Ofrecen apoio e asesoramento científico tanto ao persoal investigador da UDC como a outras universidades, organismos públicos e empresas do noso contorno. $\mathrm{O}$ centro dispón de laboratorios de Análise de Augas, Análise Estrutural, Bioloxía Molecular, Espectroscopia Molecular, Espectrometría de Plasma-Masas, Microscopia, Técnicas Cromatográficas, Técnicas Instrumentais de Análise e Xeocronoloxía.

d) Oficina de Transferencia de Resultados de Investigación (OTRI)

O seu obxectivo fundamental é favorecer as relacións entre a universidade e a empresa, procurando a transferencia da oferta científico-técnica universitaria ao sector produtivo.

\section{e) Viveiro de Empresas}

En resposta á crecente demanda de espazos para empresas, en 2004 creouse o Viveiro de Empresas da UDC, que ofrece aloxamento, asesoramento e formación a persoas emprendedoras para a posta en marcha e supervivencia dos seus proxectos empresariais. As empresas solicitantes deben ter base tecnolóxica ou certa compoñente innovadora 
e estar promovidas por membros da comunidade universitaria: alumnado, profesorado e persoal investigador ou de administración e servizos.

\section{f) Cátedras e aulas institucionais}

Pretenden potenciar a relación e a colaboración entre o mundo empresarial e o mundo universitario. No ano 2011 creouse a Cátedra INDITEX e en 2014 a Aula REPSOL e a Aula Fundación Paideia.

\section{Indicadores}

Na historia da UDC defendéronse 1.573 teses -algo máis de 65 por ano-conducentes á obtención do grao de doutor. Se no curso académico 1990-1991 se rexistraron unicamente cinco, transcorridos 11 anos ascendían xa a 87. Deseguido diminúe o número, mais desde 2009 ata 02014 defendéronse 675 teses, que representan o 42,91\% de toda a serie.

\section{Gráfico 16. Teses de doutoramento (1991-2014)}

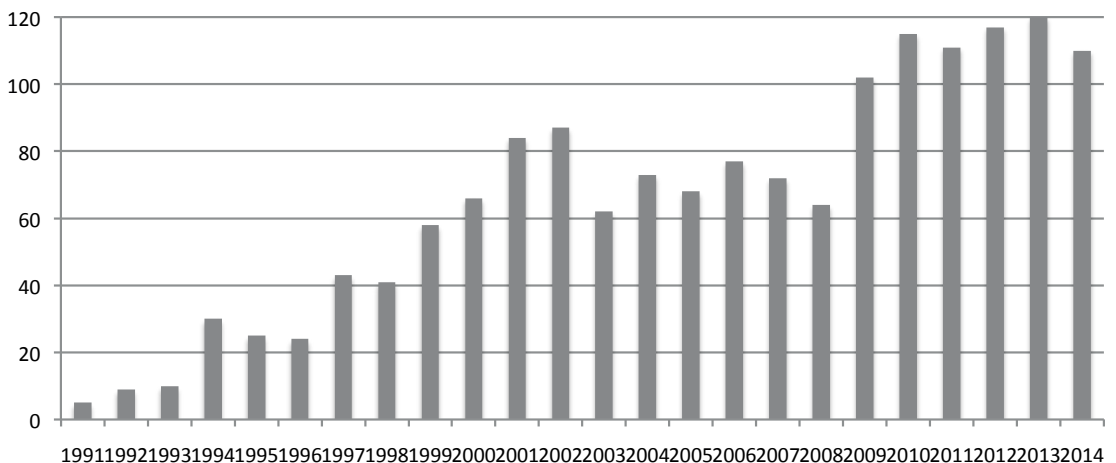

Entre 2000 e 2014 conseguíronse 1.094 proxectos de investigación competitivos, dos cales o 49,18\% se financiou con recursos autonómicos, o $44,15 \%$ estatais e o $6,67 \%$ europeos. Ata 2010 a media anual foi de algo máis de 84, oscilando entre un mínimo de 70 (2001 e 2004) e un máximo de 103 (2010), pero nos catro anos seguintes produciuse unha caída brutal debido aos recortes dos fondos públicos destinados a investigación, o que sitúa a media en 42 proxectos por ano.

Os fondos recadados ascenderon a 73.571 .842 euros, procedendo $049,33 \%$ da administración central, o 37,47\% da autonómica e o 13,20\% da europea. En comparación co indicador anterior, o peso de Europa duplícase, o do Estado aumenta cinco puntos e 0 de Galicia diminúe algo menos de 12, o que está en sintonía co importe medio dos proxectos concedidos por cada unha destas instancias: 133.016, 75.136 e 51.247 euros, respectivamente. 
Gráfico 17. Proxectos de investigación competitivos (2000-2014)

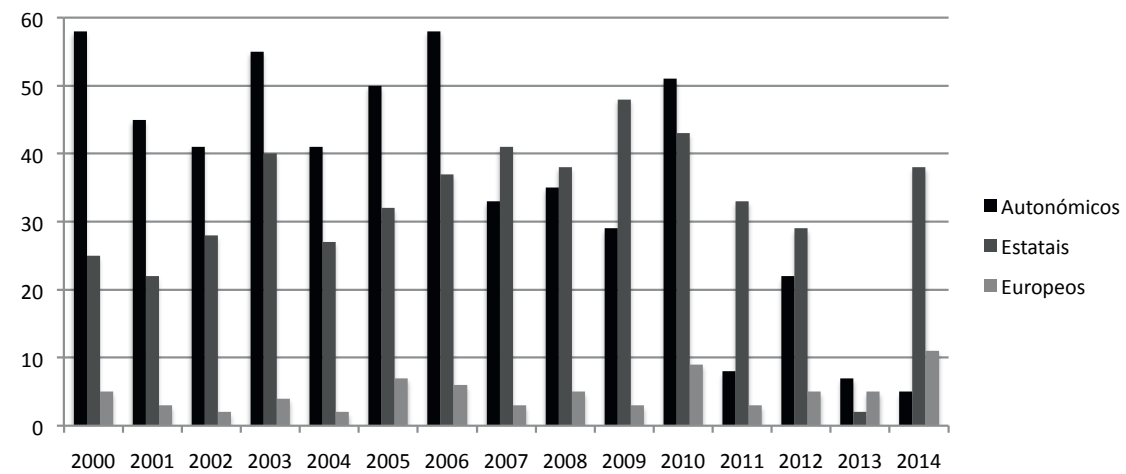

O número de contratos e convenios con empresas e administracións públicas entre 2003 e 2014 foi de 2.651, o que supón unha media de 221 por ano. 0 incremento máis notable tivo lugar en 2005 e a cifra máxima (286) acadouse en 2008. Nos últimos tres anos a tendencia é descendente, destacando a caída de 2012.

En total ingresáronse 71.460.233 euros, a unha media de 5.955.019 por ano. A cifra máxima tamén correspondeu a 2008 (10.002.991 euros), mentres que o máximo crecemento tivo lugar en 2013. O importe medio dos convenios e contratos foi de 28.101 euros, oscilando entre os 40.357 de 2004 e os 13.901 de 2014.

Gráfico 18. Contratos e convenios de investigación con empresas e administracións públicas (2003-2014)

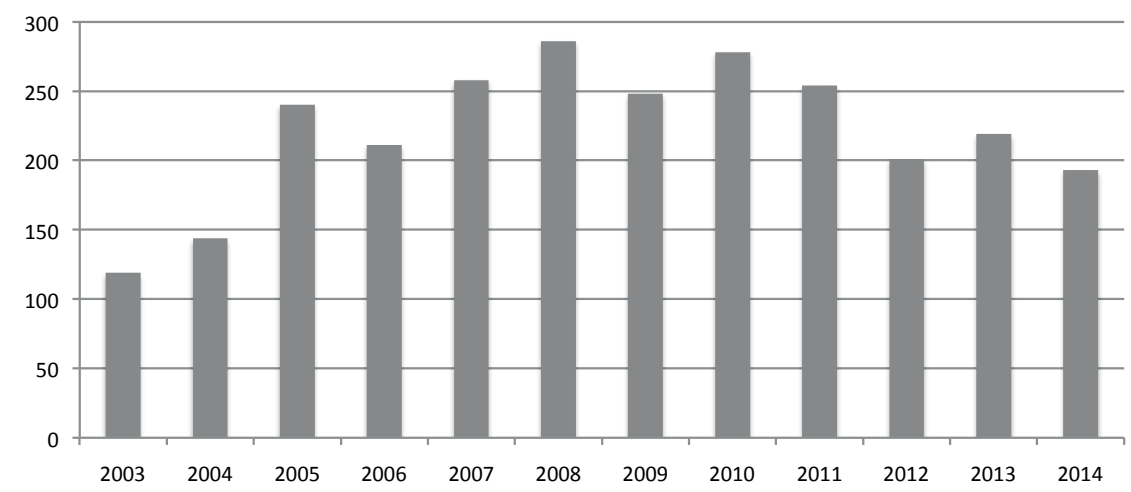

As patentes concedidas e outros rexistros da propiedade intelectual suman 222 desde 1997 -data en que se conseguiu a primeira patente-, a unha media de 12 por ano. 0 seu número experimentou importantes oscilacións, aínda que máis da metade dos rexistros están datados nos últimos cinco anos. 
Gráfico 19. Patentes concedidas e outros rexistros da propiedade intelectual (1997-2014)

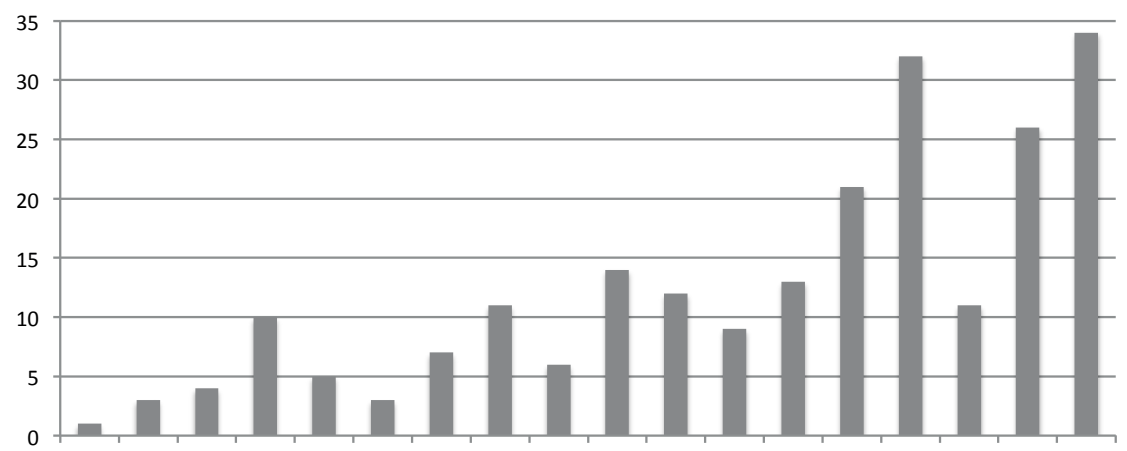

199719981999200020012002200320042005200620072008200920102011201220132014

Os traballos de investigación publicados por persoal da UDC e recollidos na Web of Science ascenden a 6.750 , dos que 5.018 corresponden a artigos, revisións e notas. A tendencia é ascendente, aínda que con algúns descensos puntuais $(1998,2010)$ ou estancamentos (2002-2005). Nos últimos seis anos produciuse $046,21 \%$ dos rexistros na Web of Science.

\section{Gráfico 20. Documentos publicados por persoal da UDC e recollidos na Web of Science} (1990-2014)

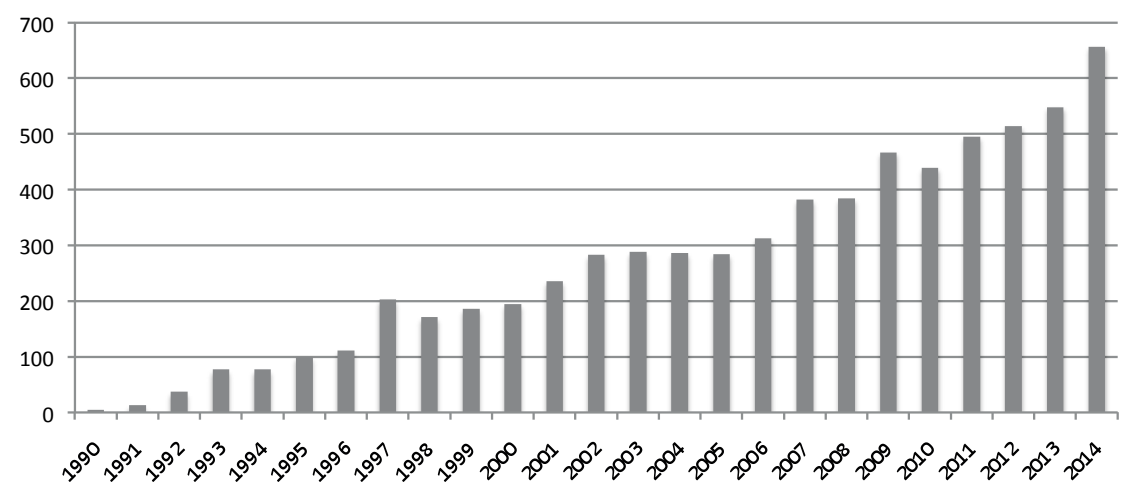

Os sexenios de investigación -complemento retributivo do profesorado que se concede en virtude da actividade investigadora- certificados pola Comisión Nacional Evaluadora de la Actividad Investigadora (CNEAI) foron $1.185 .{ }^{20}$ Este indicador, que posiblemente constitúa a expresión máis sintética e sistemática da evolución da investigación nas universi-

\footnotetext{
${ }^{20}$ En 2013 conseguíronse 98 sexenios, que non se recollen do gráfico debido á agrupación dos datos precisamente en períodos de seis anos.
} 
dades, reflicte con precisión a progresiva mellora da actividade investigadora: 0 48,69\% dos sexenios certificados desde 1989 ata 2012 conseguiuse entre 2008 e 2012.

Gráfico 21. Sexenios de investigación (1989-2012)

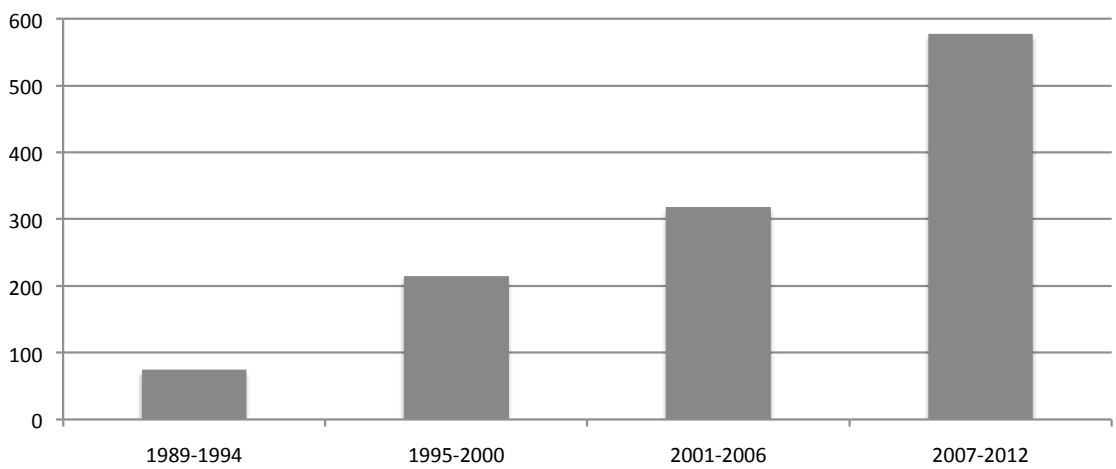

A evolución destes indicadores é, como se pode apreciar, claramente ascendente, se exceptuamos os proxectos de investigación e os convenios e contratos durante os últimos anos. A crise económica, a redución do financiamento público en materia de investigación e a demora con que se publicaron algunhas convocatorias explican os descensos e algunhas oscilacións.

\section{Consideracións finais}

A UDC é na actualidade unha universidade consolidada no tocante ás infraestruturas, o persoal e a docencia, e cunha evolución positiva da investigación, malia que neste dominio reste un longo camiño por percorrer, como poñen de manifesto as estatísticas comparativas de carácter estatal ou internacional.

No Plan estratéxico UDC2020, aprobado polo Claustro na súa sesión do 4 de decembro de 2013, identifícanse cinco áreas estratéxicas: docencia e aprendizaxe, investigación, innovación e transferencia, responsabilidade social, internacionalización e financiamento e usos eficiente dos recursos.

Agardemos que nos próximos anos se consiga seguir avanzando en todas e cada unha destas áreas. Non será posible facelo se proseguen as restricións no financiamento e os poderes públicos continúan sen apostar de forma decidida pola formación e a investigación. 